\title{
PLASMA RICO EM PLAQUETAS E FATORES DE CRESCIMENTO: TÉCNICA DE PREPARO E UTILIZAÇÃO EM CIRURGIA PLÁSTICA
}

\section{PLATELET-RICH PLASMA AND GROWTH FACTORS: PROCESSING TECHNIQUE AND APPLICATION IN PLASTIC SURGERY}

\author{
Fabiel Spani Vendramin, TCBC-RJ'1; Diogo Franco, TCBC-RJ'2; Carmen Martins Nogueira; \\ Mariana Sá Pereira ${ }^{4}$; Talita Romero Franco, ECBC-RJ
}

\begin{abstract}
RESUMO: Objetivo: Estabelecer um método barato e eficiente de preparação do plasma rico em plaquetas e fatores de crescimento para utilização em cirurgia plástica. Método: Foram realizados 20 testes através de centrifugação de sangue, variando-se a força e o tempo de centrifugação, para determinarmos o melhor método que proporcione uma maior concentração plaquetária e mais 10 testes para comprovar a reprodutibilidade do método. Resultados: A utilização de uma força de centrifugação de $300 \mathrm{~g}$ por 10 minutos na $1^{\mathrm{a}}$. centrifugação e de $640 \mathrm{~g}$ por 10 minutos na $2^{\mathrm{a}}$. centrifugação obtiveram as maiores concentrações plaquetárias, superiores a 4,5 vezes a concentração na amostra, e os testes foram reprodutíveis. Conclusão: Uma alta concentração plaquetária pode ser obtida por este protocolo de obtenção de plasma rico em plaquetas e fatores de crescimento e a formação do gel é possível através da utilização de trombina autóloga, também obtida pelo protocolo descrito, facilitando sua utilização em cirurgia plástica, onde vem mostrando bons resultados na cicatrização de feridas e na integração de enxertos ósseos e cutâneos (Rev. Col. Bras. Cir. 2006; 33(1): 24-28).
\end{abstract}

Descritores: Procedimentos cirúrgicos reconstrutivos; Cicatrização de feridas; Fator de crescimento derivado de plaquetas; Fator de crescimento transformador beta; Plaquetas.

\section{INTRODUÇÃO}

O plasma rico em plaquetas (PRP) tem sido bastante estudado na área de odontologia, sendo empregado principalmente em pequenos enxertos ósseos na região alveolar para futuros implantes dentários e em cirurgias periodontais e maxilo-faciais ${ }^{1-5}$. Sua utilização em medicina ainda é pequena, porém os estudos existentes sobre este produto mostram um grande potencial de melhorar os resultados em diversos procedimentos ortopédicos, neurocirúrgicos e de cirurgia plásti$\mathrm{ca}^{6-12}$. O PRP é uma concentração autóloga de plaquetas em um pequeno volume de plasma, com a conseqüente presença de fatores de crescimento (FC) liberados por estas plaquetas, além de proteínas osteocondutoras, que também servem de matriz para migração epitelial e formação óssea e de tecido conectivo $^{3,7,13,14}$.

As plaquetas atuam no processo de hemostasia, cicatrização de feridas e re-epitelização. Elas liberam diversos FC que estimulam a angiogênese, promovendo crescimento vascular e proliferação de fibroblastos, que por sua vez proporcionam um aumento na síntese de colágeno ${ }^{3,9,15-18}$. Estas propriedades das plaquetas tornam o PRP um produto com grande potencial de melhorar a integração de enxertos, sejam eles ósseos, cutâneos, cartilaginosos ou de gordura, bem como estimular a cicatrização de feridas. Nas cirurgias em que se trabalha com retalhos cutâneos, inclusive mamoplastias, abdominoplastias e ritidoplastias, o PRP ajuda na hemostasia e estimula o desenvolvimento da neovascularização, diminuindo assim complicações como hematomas, seromas e sofrimento vascular dos retalhos ${ }^{6,11}$. Estas propriedades podem ser empregadas para melhorar o tratamento de feridas no membro inferior que costumam evoluir com uma cicatrização mais lenta e com a incidência de complicações nos retalhos locais maior que em outras partes do corpo ${ }^{10-12}$.

O gel de PRP é obtido através da adição de trombina e gluconato de cálcio ao PRP. Estes ativam o sistema de coagulação, resultando na gelação do PRP, o que facilita sua aplicação em diversas cirurgias e também ativam as plaquetas $^{19,20}$. Inicialmente o PRP era obtido através de máquinas de plasmaferese e utilizava-se a trombina bovina para sua ativação. $\mathrm{O}$ interesse em facilitar sua obtenção e diminuir os custos fez com que surgissem algumas máquinas

1. Mestre em Cirurgia Plástica pela Universidade Federal do Rio de Janeiro (UFRJ); Médico do Serviço de Cirurgia Plástica do Hospital Central da Polícia Militar do Estado do Rio de Janeiro (HCPM) e do Hospital dos Servidores do Estado do Rio de Janeiro (HSE).

2. Doutor em Cirurgia Plástica pela Universidade Federal do Rio de Janeiro; Médico do Serviço de Cirurgia Plástica do Hospital Universitário Clementino Fraga Filho (UFRJ).

3. Professora Auxiliar do Departamento de Clínica Médica da Universidade Federal do Rio de Janeiro; Chefe do Serviço de Hemoterapia do Hospital Universitário Clementino Fraga Filho (UFRJ).

4. Professora Adjunta do ICB - Laboratório de Tecido Conjuntivo da Universidade Federal do Rio de Janeiro - UFRJ.

5. Professora Titular de Cirurgia Plástica da Universidade Federal do Rio de Janeiro; Chefe do Serviço de Cirurgia Plástica do Hospital Universitário Clementino Fraga Filho (UFRJ).

Recebido em:15/08/2005

Aceito para publicação em:18/10/2005

Conflito de interesses: nenhum

Fonte de financiamento: nenhuma

Trabalho realizado no Serviço de Cirurgia Plástica e no Serviço de Hematologia do HUCFF - UFRJ, vinculado ao programa de Pós-Graduação do Departamento de Cirurgia. 
automatizadas e diversos protocolos, inclusive com substituição da trombina bovina por trombina autóloga $a^{2,21}$. As máquinas automatizadas com seus "kits" tornam simples a obtenção do PRP, porém os custos ainda são elevados. Assim, alguns protocolos foram criados para se obter pequenas quantidades de PRP e trombina autólogos, utilizando-se centrífugas comuns e reduzindo muito os custos na preparação do produto $^{19,22}$.

Neste trabalho serão mostrados os estudos desenvolvidos no Serviço de Cirurgia Plástica do Hospital Universitário Clementino Fraga Filho (UFRJ), em conjunto com o Serviço de Hemoterapia e o Laboratório de Tecido Conjuntivo, com a intenção de estabelecer um protocolo de obtenção do gel de plaquetas e fatores de crescimento e da trombina autóloga, bem como um comentário sobre os resultados iniciais com a aplicação do produto em enxertos ósseos, cutâneos e na cicatrização de feridas.

\section{MÉTODO}

Foram realizados 30 testes, promovendo a centrifugação de amostras de sangue, variando-se a força $(g)$ e o tempo (T) de centrifugação, sendo o produto final submetido à dosagem de plaquetas. Analisamos os resultados para determinar os melhores $g$ e T, que resultavam em maiores concentrações de plaquetas, buscando-se um aumento mínimo de $400 \%$ da concentração plaquetária em relação ao sangue testado. Vinte testes iniciais serviram para estabelecer o protocolo que conseguisse uma maior concentração de plaquetas e outros dez testes obedeceram a este protocolo, objetivando verificar a reprodutibilidade do método.

Em cada teste foram utilizados dois tubos Falcon, cada um com $10 \mathrm{ml}$ de sangue, que foram submetidos à primeira centrifugação (centrífuga JOUAN BR 4i) promovendo a separação das células vermelhas que, por terem um peso específico maior, depositam-se na parte inferior do tubo. Na parte superior fica o plasma com as plaquetas e, entre estas duas camadas, existe uma outra fina e esbranquiçada, denominada de zona de névoa, que contém as células brancas, principalmente leucócitos, e as plaquetas maiores. Com uma pipeta milimetrada foram colhidos 50 microlitros da porção superior do plasma de cada um dos tubos, totalizando $1,0 \mathrm{ml}$, que foi colocado em outro tubo Falcon (Tubo A), para obtermos a trombina autóloga. Neste $1 \mathrm{ml}$ de plasma foram adicionados $0,3 \mathrm{ml}$ de gluconato de cálcio a $10 \%$ e o tubo foi colocado em banho-maria por 15 minutos. Durante este tempo, foram pipetados o restante do plasma e a zona de névoa que foram acondicionados em outro tubo Falcon (Tubo B). Os tubos A (após o banho-maria) e $\mathrm{B}$ foram submetidos à nova centrifugação, que resultou na separação de um líquido rico em trombina no tubo A e na sedimentação das plaquetas (e algumas hemácias) no fundo do tubo B. Foi retirada a porção superior do plasma no tubo B, que era o plasma pobre em plaquetas (PPP), até a redução de $50 \%$ do volume total do plasma neste tubo. O tubo B foi agitado para dispersar as plaquetas no plasma restante, obtendo-se assim o PRP.

A concentração da trombina existente no tubo A foi medida através de ensaio de atividade amidolítica, utilizando substrato cromogênico específico para a enzima (S-2238). Para o cálculo da concentração, foram utilizados os resultados de uma curva padrão obtidos com testes feitos com trombina humana purificada.

A qualidade do PRP obtido em cada teste foi feita por contagem de plaquetas através de microscópio (INALH-MEB215-T). Analisamos a força $(g)$ e o tempo (T) de centrifugação, correlacionando com a qualidade do PRP, para que fosse determinado o protocolo de obtenção de PRP. Em seguida, dez testes foram realizados seguindo-se o protocolo para que fosse definida a reprodutibilidade do mesmo.

\section{RESULTADOS}

As tabelas 1 e 2 mostram as médias das concentrações plaquetárias no PRP em relação à amostra de sangue, de acordo com a força $(g)$ e o tempo $(\mathrm{T})$ de centrifugação nas $1^{\mathrm{a}}$. e $2^{\mathrm{a}}$. etapas de centrifugação, respectivamente. Na primeira centrifugação, as maiores concentrações plaquetárias no PRP foram obtidas quando utilizamos a força de $300 \mathrm{~g}$ por um tempo de 10 minutos, onde observamos uma média de 4,54 ( $\pm 0,71)$ vezes superior ao da amostra de sangue. Na segunda centrifugação, as maiores concentrações plaquetárias no PRP foram alcançadas quando utilizamos a força de $640 \mathrm{~g}$ por 10 minutos, onde obtivemos uma média de 4,96 $( \pm 0,36)$ vezes superior ao da amostra de sangue.

A concentração da trombina ativa medida no líquido do tubo A foi de $27,9( \pm 3,54) \mathrm{U} / \mathrm{ml}$.

Na etapa de verificação da reprodutibilidade do método, observamos que ele é reprodutível e promoveu uma concentração plaquetária em média $4,19( \pm 0,09)$ vezes maior que a medida na amostra de sangue, o que foi um pouco menor que a observada nos testes iniciais.

\section{DISCUSSÃo}

O PRP é um produto que promove um forte estímulo para a cicatrização ${ }^{7,9,12,13,18}$. Foram identificados pelo menos

Tabela 1 - Média da concentração plaquetária do PRP de acordo com a variação do tempo e da força de centrifugação na $1^{a}$ etapa.

\begin{tabular}{rrc}
\hline $\mathbf{T} \backslash \boldsymbol{g}$ & $\mathbf{3 0 0}$ & $\mathbf{4 6 0}$ \\
$\mathbf{1 0}$ & 4,54 & 4,37 \\
$\mathbf{1 5}$ & 3,10 & - \\
\hline
\end{tabular}

$T=$ tempo de centrifugação; $g=$ força de centrifugação.

Tabela 2 - Média da concentração plaquetária do PRP de acordo com a variação do tempo e da força de centrifugação na $2^{a}$ etapa.

\begin{tabular}{rrrc}
\hline $\mathbf{T} \backslash \boldsymbol{g}$ & $\mathbf{4 6 0}$ & $\mathbf{6 6 0}$ & $\mathbf{7 5 2}$ \\
$\mathbf{1 0}$ & 4,35 & 4,96 & 3,10 \\
$\mathbf{1 5}$ & 3,10 & 4,44 & - \\
\hline
\end{tabular}

$T=$ tempo de centrifugação $; g=$ força de centrifugação. 

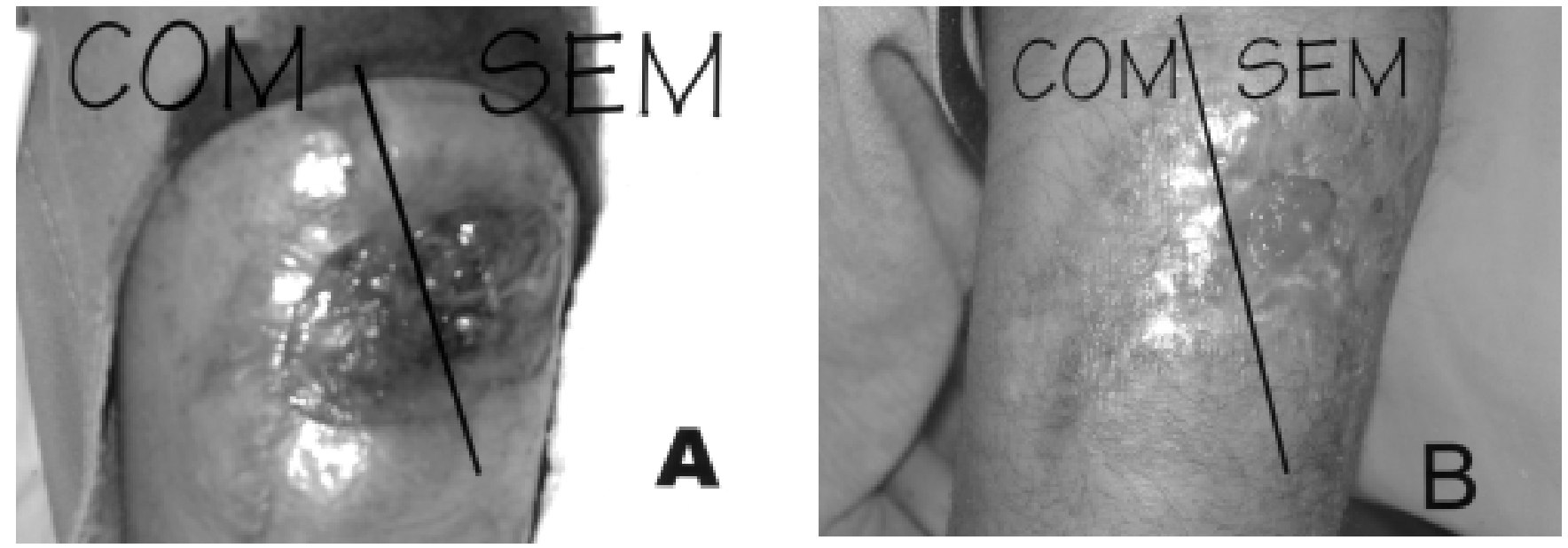

Figura 1 - Paciente com ferida traumática, tratada com enxerto de pele parcial. A: Pré-operatório. Na parte esquerda da ferida, em seu leito, foi colocado o gel de PRP, sob o enxerto, e na parte direita foi realizado o enxerto de modo convencional, sem o gel de PRP. B: Aspecto com 1 mês de pós-operatório, evidenciando cicatrização completa no lado em que foi utilizado o gel e perda de 67,2\% do enxerto (software Scion Image) no lado em que não o utilizamos.

sete diferentes fatores de crescimento secretados ativamente pelas plaquetas e que atuam na fase inicial da cicatrização. São eles: três isômeros do fator de crescimento plaquetário (PDGF) - PDGF $\alpha \alpha$, PDGF $\beta$ e PDGF $\alpha$ - dois fatores de crescimento transformadores (TGF) - TGF $\beta 1$ e TGF $\beta 2$ - o fator de crescimento endotelial vascular (VEGF) e o fator de crescimento epitelial (EGF) ${ }^{3,8,9,18}$. Os TGF ativam os fibroblastos para formação de protocolágeno, que resulta na deposição de colágeno e cicatrização da ferida. Os PDGF, associados ou não com os TGF, aumentam a vascularização tissular, promovem a proliferação de fibroblastos, aumentam a quantidade de colágeno, estimulam produção de tecido de granulação e melhoram a osteogênese $e^{2,9,17,23}$. O VEGF estimula a angiogênese, a mitogênese e a permeabilidade vascular e o EGF induz o crescimento de tecido epitelial e promove também a angiogênese. Estas substâncias tornam a cicatrização mais rápida e eficiente, favorecendo a integração de enxertos, sejam eles ósseos, cutâneos, cartilaginosos ou de células de gordura. Além disto, o PRP possui proteínas como a fibrina, fibronectina e vitronectina, que promovem a osteocondução através de sua ação na adesão celular, além da própria ação do TGFß e do PDGF na estimulação dos osteoclastos, melhorando a qualidade dos resultados obtidos nas enxertias ósseas $^{3,23,24}$.

As primeiras formas de extração do PRP autólogo para utilização em cirurgias empregavam máquinas de autotransfusão para fazer a separação celular do sangue que circulava por ela proveniente de um cateter venoso profundo colocado no paciente durante a cirurgia. Eram necessários 400 a $450 \mathrm{ml}$ de sangue e um técnico especializado para operar esta máquina ${ }^{9,21,22,25}$. Isto limitava a obtenção do PRP a um centro cirúrgico de grande porte e representava maior morbidade para o paciente. A intenção de simplificar o método levou ao desenvolvimento de protocolos utilizando aparelhos mais simples (AG Curasan ${ }^{\circledast}, 3$ i PCCS ${ }^{\circledR}$, Sequire $^{\circledR}$ e SmartPReP ${ }^{\circledR}$ ) que obtinham em torno de 7 a $10 \mathrm{ml}$ de PRP a partir de 50 a $60 \mathrm{ml}$ de sangue retirados através de punção venosa periférica ${ }^{21}$. No Brasil, dispomos de kits importados para obtenção do PRP pelo sistema automatizado, porém os custos ficam em torno de $\mathrm{R} \$ 2.300,00$. A possibilidade de se obter PRP com custos menores, utilizando-se uma centrífuga convencional, fez surgir alguns protocolos que, embora sejam mais trabalhosos e necessitem de aprendizagem por parte de quem irá realizar o procedimento, permitem a preparação do PRP com custo dez vezes menor e em ambientes mais simples, desde que possuam uma centrífuga.

Com este protocolo conseguimos alcançar uma concentração plaquetária em média pelo menos quatro vezes superior ao da amostra de sangue. Esta concentração é maior que a observada em outros protocolos como o de Anitua e o de Landesberg, que não conseguiram chegar a um aumento de duas vezes a concentração plaquetária no sangue do paciente, segundo verificado no trabalho de $\mathrm{Marx}^{3}$, e semelhante às concentrações obtidas pelos métodos automatizados, que variam de um, seis a quatro vezes superiores à do sangue dos pacientes ${ }^{21}$. O método também se mostra reprodutível e de fácil aplicação, desde que executado por uma pessoa treinada. Sua preparação demora cerca de 45 minutos, após a coleta do sangue.

Em relação à trombina autóloga, necessária para a formação do gel, nosso protocolo de obtenção mostrou a presença de $27,9 \mathrm{U} / \mathrm{ml}$ de trombina ativa no líquido coletado do tubo A. Assim, comprovamos que este líquido é rico em trombina ativa e, na prática, promove o efeito desejado de gelação do PRP.

Adaptamos este protocolo para aplicação na prática médica e estamos utilizando o PRP em enxertos cutâneos, enxertos ósseos e na cicatrização de feridas. Em relação aos enxertos, observamos melhor integração dos mesmos, com melhor resultado final da cirurgia (Figura1). Em relação às feridas, observamos uma diminuição mais rápida no seu tamanho, bem como o desenvolvimento de um tecido de granulação de melhor qualidade, com uma vascularização mais intensa (Figura 2). Nas regiões doadoras de pele parcial, percebemos que o curativo com PRP torna a primeira troca menos dolorosa e a epitelização da ferida mais rápida. 

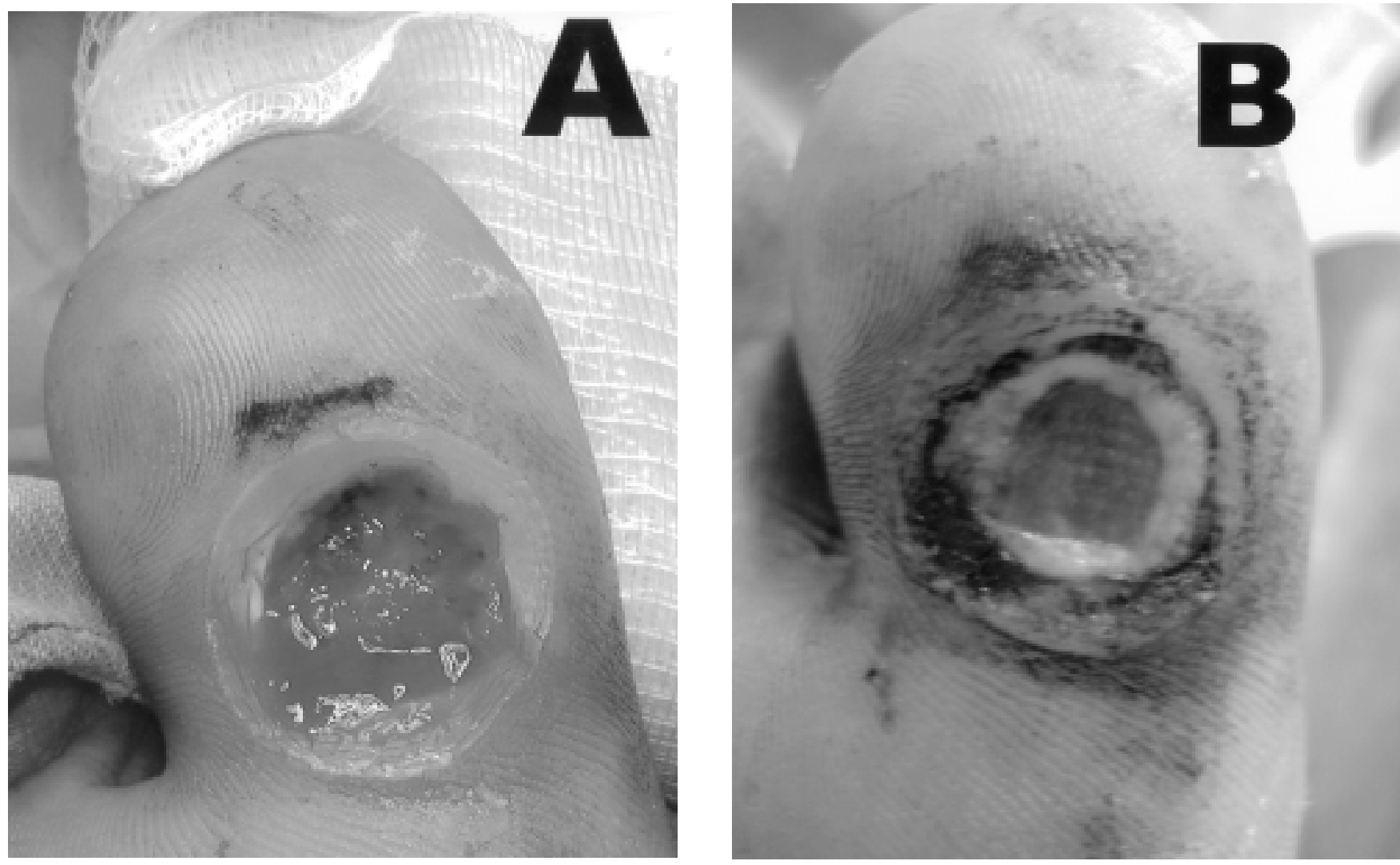

Figura 2 - Tratamento de mal perfurante plantar em um paciente diabético, através de exérese e curativo da ferida com gel de PRP. A: Ferida profunda resultante da exérese da lesão. B: Aspecto no quinto dia de evolução, após a primeira troca de curativo. Redução de 58,6\% do tamanho da ferida (software Scion Image) e nivelação do leito da ferida com a pele do paciente.

A obtenção do gel de PRP e fatores de crescimento pode ser feita de forma mais econômica e em locais sem muitos recursos tecnológicos, mas que disponham de uma centrífuga e materiais usualmente presentes em ambientes hospitalares como seringas, agulhas e tubos de coleta de sangue. $\mathrm{O}$ treina- mento de pessoal é a condição específica para ser possível a aplicação rotineira do método e, passado este momento inicial de aprendizado e ajuste, a expectativa é de melhoria nos resultados obtidos e, possivelmente, aplicabilidade em outras situações.

\begin{abstract}
Background: Platelet-rich plasma is an autologous concentration of human platelets in a small volume of plasma. The vast majority of publications reports a significant healing enhancement following its use. This study aim to establish a low-cost method to prepare a platelet-rich plasma and growth factors to be used in plastic surgery. Methods: Blood was submitted to two centrifugations to obtain platelet-rich plasma. Twenty tests were performed changing the intensity and time of centrifugation, aim to establish the method that achieves the optimal platelet enrichment; and ten tests were performed to confirm the reproducibility of this method. Results: The optimal platelets enrichment, over 4.5 times baseline, values was obtained using $300 \mathrm{~g}$ for 10 minutes on the first centrifugation and $640 \mathrm{~g}$ for 10 minutes on the second centrifugation. Conclusions: Platelet-rich plasma with high platelets counts can be prepared using this method and the gel can be obtained with the addition of autologous thrombin, obtained in the same procedure. This autologous platelet gel enhanced wound healing, therefore showing improved results in skin and bone grafts.
\end{abstract}

Key words: Reconstructive surgical procedures; Wound healing; Platelet-derived growth factor; Transforming growth factor beta; Blood platelets.

\section{REFERÊNCIAS}

1. Anitua E. The use of plasma-rich growth factors (PRGF) in oral surgery. Pract Proced Aesthet Dent. 2001;13(6):487-93.

2. Lozada JL, Caplanis N, Proussaefs P, et al. Platelet-rich plasma application in sinus graft surgery: Part I - Background and processing techniques. J Oral Implantol. 2001;27(1):38-42.
3. Marx RE. Platelet-rich plasm: evidence to support its use. J Oral Maxillofac Surg. 2004;62(4):489-96.

4. Oyama T, Nishimoto S, Tsugawa T, et al. Efficacy of plateletrich plasma in alveolar bone grafting. J Oral Maxillofac Surg. 2004;62(5):555-8.

5. Whitman DH, Berry RL. A technique for improving the handling of particulate cancellous bone and marrow grafts using platelet gel. J Oral Maxillofac Surg. 1998;56(10):1217-8. 
6. Bhanot S, Alex JC. Current applications of platelet gels in facial plastic surgery. Facial Plast Surg. 2002;18(1):27-33.

7. Crovetti G, Martinelli G, Issi M, et al. Platelet gel for healing cutaneous chronic wounds. Transfus Apher Sci. 2004;30(2):14551.

8. Freymiller EG, Aghaloo TL. Platelet-rich plasma: ready or not? J Oral Maxillofac Surg. 2004;62(4):484-8.

9. Green DM, Klink B. Platelet gel as an intraoperatively procured platelet-based alternative to fibrin glue. Plast Reconstr Surg.1998;101(4):1161-2.

10. Linkhart TA, Mohan S, Baylink DJ. Growth factors for bone growth and repair: IGF, TGFâ and BMP. Bone. 1996;19(1 Suppl.):1S-12S.

11. Man D, Plosker H, Winland-Brown JE. The use of autologous platelet-rich plasma (platelet gel) and autologous platelet-poor plasma (fibrin glue) in cosmetic surgery. Plast Reconstr Surg. 2001;107(1):229-37; discussion 238-9.

12. Mazzucco L, Medici D, Serra M, et al. The use of autologous platelet gel to treat difficult-to-heal wounds: a pilot study. Transfusion. 2004;44(7):1013-8.

13. Haynesworth SE, Kadiyala S, Liang L, et al. Chemotactic and mitogenic stimulation of human mesenchymal stem cells by platelet rich plasma suggests a mechanism for enhancement of bone repair. $48^{\text {th }}$ Annual Meeting of the Orthopaedic Research Society. Dallas, TX, 2002.

14. Henderson JL, Cupp CL, Ross EV, et al. The effects of autologous platelet gel on wound healing. Ear Nose Throat J. 2003;82(8):598602.

15. Antoniades HN, Williams LT. Human platelet-derived growth factor: structure and function. Fed Proc. 1983;42(9):2630-4.

16. Dvorak HF, Brown LF, Detmar M, et al. Vascular permeability factor / vascular endothelial growth factor, microvascular hyperpermeability, and angiogenesis. Am J Pathol. 1995;146(5):1029-39.
17. Liu Y, Kalén A, Risto O, et al. Fibroblast proliferation due to exposure to a platelet concentrate in vitro is $\mathrm{pH}$ dependent. Wound Repair Regen. 2002;10(5):336-40.

18. Robson MC. The role of growth factors in the healing of chronic wounds. Wound Repair Regen.1997;5(1):12-17.

19. Efeoglu C, Akcay YD, Ertürk S. A modified method for preparing platelet-rich plasma: an experimental study. J Oral Maxillofac Surg. 2004;62(11):1403-7.

20. Lindemann S, Tolley ND, Dixon DA, et al. Activated platelets mediate inflammatory signaling by regulated interleukin 1â synthesis. J Cell Biol. 2001;154(3):485-90.

21. Kevy SV, Jacobson MS. Comparison of methods for point of care preparation of autologous platelet gel. J Extra Corpor Technol. 2004;36(1):28-35.

22. Pacifici L, Casella F, Maggiore C. Plasma arricchito di piastrine (PRP): metodi di estrazione e potenzialità d'uso. Minerva Stomatol. 2002;51(7-8):341-50.

23. Knox P, Crooks S, Rimmer CS. Role of fibronectin in the migration of fibroblasts into plasma clots. J Cell Biol. 1986;102(1):231823.

24. Sandy J, Davies M, Prime S, et al. Signal pathways that transducer growth factor-stimulated mitogenesis in bone cells. Bone. 1998;23(1):17-26.

25. Marx RE, Carlson ER, Eichstaedt RM, et al. Platelet-rich plasma: growth factors enhancement for bone grafts. Oral Surg Oral Med Oral Pathol Oral Radiol Endod. 1998;85(6):638-46.

Endereço para correspondência:

Fabiel Spani Vendramin

Travessa Quintino Bocaiuva, 718

Reduto - CEP: 66053-240

Belém - Pará 